\title{
Survival Analysis in Elderly Patients with Glioblastomas: The Influence of Clinical Status, Tumor and Surgical Features
}

\section{Análise de sobrevivência em pacientes idosos com glioblastomas: influência de status clínico, aspectos oncológicos e cirúrgicos}

\author{
Ulysses Oliveira Sousa ${ }^{1}$ Matheus Fernandes Oliveira ${ }^{1}$ Lindolfo Carlos Heringer ${ }^{1}$ \\ Ricardo Vieira Botelho ${ }^{1}$ José Marcus Rotta ${ }^{1}$ \\ ${ }^{1}$ Department of Neurosurgery, Hospital do Servidor Público Estadual \\ de São Paulo, São Paulo, SP, Brazil \\ Address for correspondence Matheus Fernandes de Oliveira, PhD, \\ Departmento de Neurocirurgia, Hospital do Servidor Público Estadual \\ de São Paulo, IAMSPE, Rua Loefgren, 700, apto 103, Vila Clementino, \\ Arq Bras Neurocir 2018;37:297-303. \\ São Paulo, SP 04040-000, Brazil (e-mail: mafernoliv@yahoo.com.br).
}

\begin{abstract}
Introduction Glioblastomas are malignant neoplasms, notorious for their poor prognosis. We have conducted a survival analysis in a sample of elderly patients with glioblastomas.

Methods The sample of the present study consisted of elderly patients consecutively admitted from January 2014 to January 2016 (24 months) at the Hospital do Servidor Público Estadual de São Paulo. We have evaluated the impact of age, Karnofsky scale (KS) score, tumor location, and occurrence of perioperative complications.

Results A total of 42 patients were analyzed. Of these, 23 (54.7\%) were men, and 19 (45.3\%) were women. Patients $>60$ years old, with low KS score, deep-seated tumors, and those with perioperative complications had worst outcomes.

Discussion and conclusion Surgery, perioperative chemotherapy and radiotherapy

Keywords

- neoplasms

- glioblastoma

- prognosis

\section{Resumo} add survival time and quality of life to these patients. In patients with low KS score, isolated radiotherapy and/or chemotherapy might be adequate. Decreasing perioperative complications is essential to adequately deliver adjuvant therapy in elderly patients.

Introdução Os glioblastomas são neoplasias malignas, notórios por seu mau prognóstico. Realizamos uma análise de sobrevivência em uma amostra de pacientes idosos com glioblastomas.

Métodos A amostra consistiu de pacientes idosos admitidos consecutivamente de janeiro de 2014 a janeiro de 2016 (24 meses) no Hospital do Servidor Público Estadual de São Paulo. Avaliamos o impacto da idade, da pontuação na escala de Karnofsky (KS, na sigla em inglês), da localização do tumor e da ocorrência de complicações pósoperatórias.
\end{abstract}

received

May 19, 2018

accepted

August 31, 2018

published online

November 6, 2018
DOI https://doi.org/

10.1055/s-0038-1675364. ISSN 0103-5355.
Copyright (e 2018 by Thieme Revinter

Publicações Ltda, Rio de Janeiro, Brazil
License terms

(ㄷ) (i) $\ominus$ (5) 
Resultados Um total de 42 pacientes foram analisados, dos quais 23 (54.7\%) eram homens e 19 (45.3\%) eram mulheres. Pacientes com idade $>60$ anos, com uma pontuação KS baixa, tumores profundos e aqueles com complicações pós-operatórias apresentaram os piores resultados.

Discussão e Conclusão A cirurgia, quimioterapia e radioterapia aumentam a sobre-

Palavras-chave

- neoplasias

- glioblastoma

- prognóstico vida e a qualidade de vida desses pacientes. Em pacientes com uma pontuação KS baixa, a radioterapia isolada e/ou quimioterapia podem ser adequadas. A redução das complicações perioperatórias é essencial para permitir a realização adequada do tratamento adjuvante em pacientes idosos.

\section{Introduction}

High grade gliomas (HGG) are malignant neoplasms, notorious for their poor prognosis, and glioblastomas (GBs) are the most aggressive and frequent among them. The mean age at the time of the diagnosis of GBs is between the $5^{\text {th }}$ and $6^{\text {th }}$ decades of life, with a recent increase in the number of patients $>70$ years old. This diagnosis is becoming more common due to the aging of the population and to the popularization of imaging examinations. ${ }^{1-9}$

Managing elderly patients with this condition is challenging. Some questions concerning GBs in the elderly include surgical strategy (biopsy, subtotal resection, gross total resection), adjuvant therapy, and survival time. A clear knowledge of the natural history of the disease is still lacking and, therefore, many clinical trials in oncology exclude elderly patients, including some of those due to malignant brain tumors, which results in less evidence to guide the treatment of these patients. ${ }^{10-19}$

Elucidating the behavior of GBs in elderly patients and the potential factors associated with the natural history of the disease and survival time is fundamental to establish proper treatment, since optimal patients may be treated with the whole current oncologic portfolio. On the other hand, patients with a poor prognosis should be included in less aggressive protocols. ${ }^{20-29}$

We have conducted a survival analysis in a sample of elderly patients with GB. We have evaluated the impact of age, gender, Karnofsky scale (KS) score, tumor location and occurrence of perioperative complications.

\section{Methods}

The study sample consisted of patients with GBs admitted consecutively from January 2014 to January 2016 (24 months) at the Hospital do Servidor Público Estadual de São Paulo (HSPE-SP). We have enrolled the patients in the study and followed them up while they were under treatment for GB.

The project was approved by the Research Ethics Committee of the HSPE-SP.

We have evaluated the impact of age, gender, KS score, tumor location and laterality, and the occurrence of complications. Additionally, we have described the influence of postoperative complications in the beginning of adjuvant treatment and its impact on the final survival time.

\section{Glioblastoma Treatment Protocol}

The rationale for GB treatment adopted in our service is maximum surgical resection with optimal functional preservation and ulterior radiation therapy (RT) and chemotherapy with temozolomide (TMZ).

Standard adjuvant therapy to eligible patients consists of between 50 and $60 \mathrm{~Gy}$ of radiotherapy (RT) divided in 30 sessions (a total of 42 days of therapy). During the RT treatment, the patients also received TMZ at a daily dose of $75 \mathrm{mg} / \mathrm{m}^{2}$. After finishing the RT treatment, the TMZ dose was increased to $150 \mathrm{mg} / \mathrm{m}^{2}$ and administered for 5 consecutive days in each following 12 months.

\section{Definition of Location}

When evaluating the radiological images, obtained through magnetic resonance imaging (MRI), we applied the following definitions: cortical tumor-superficial in a single lobe; multilobar tumor-superficial in more than one lobe; deep tumor-involves the thalamus, the brainstem, the basal ganglia or corpus callosum; and insular tumor-involves predominantly the insula ( $\mathbf{- F i g . 1} \mathbf{1})$. We have also analyzed the presence of unilateral and bilateral tumors.

\section{Statistics}

The parametric numerical data were expressed as mean \pm standard deviation (SD), and the nonparametric data as median and percentages.

Kaplan-Meier curves were used for the analyses of survival time, and the Mantel-Cox regression test and log-rank tests were used to compare the Kaplan-Meier curves. The significance level was established as $p<0.05$. All of the analyses were performed with the IBM SPSS Statistics for Windows, version 20.0 (IBM Corp, Armonk, NY, USA) software package.

\section{Results}

\section{Sample Data}

A total of 47 patients underwent GB treatment during 2 years of evaluation. Five (10.6\%) were excluded due to an incomplete follow-up or to loss of contact. Finally, 42 patients were 


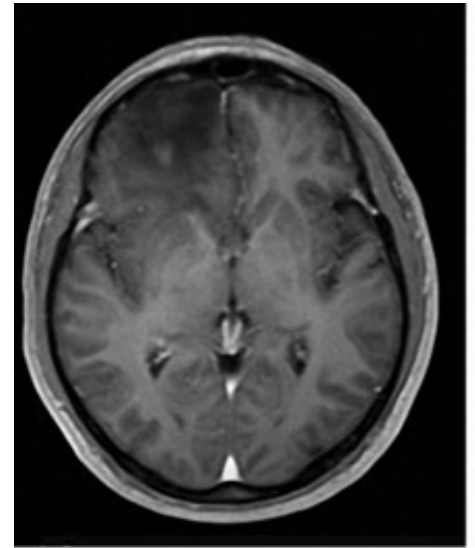

Unilobar

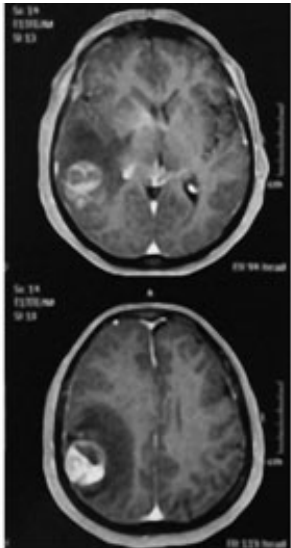

Multilobar

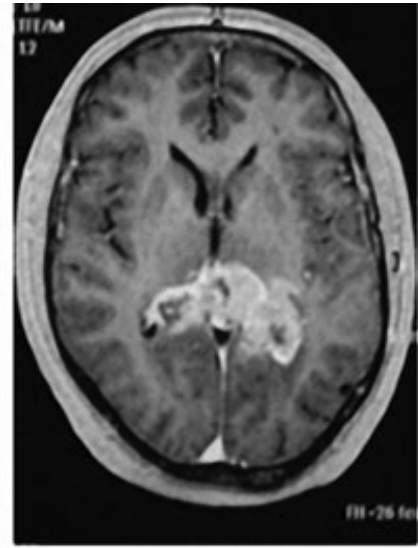

Deep

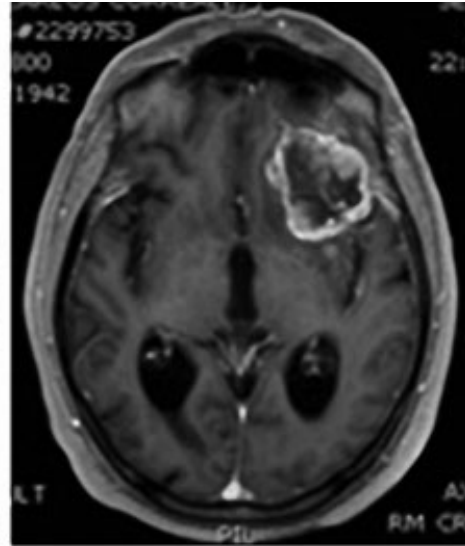

Insular

Fig. 1 Classification according to the location of the tumor.

analyzed. Of these, 23 (54.7\%) were men and 19 (45.3\%) were women. The mean age was 64.4 years old, ranging from 43 to 79 years old. The mean age among men was 66.9 years old, and 61.6 years old among women. There was no statistically significant difference between the ages of women and men.

Two of the patients (with lower KS score and deep-seated tumors) underwent stereotactic biopsy, and the other 39 underwent open surgery with maximal resection combined with maximal functional preservation.

\section{Factors Related to Survival (-Table 1)}

Age and Gender

We have tested the impact of age in three scenarios. In the first scenario, we have compared patients $<60$ years old with those $>60$ years old. In the second scenario, we have used the age of 70 years old as a threshold. In the third scenario, we have used the age of 75 years old as a threshold (-Fig. 2).

In the first scenario, patients $<60$ years old had a mean survival time of 191 days, while patients $>60$ years old had a mean survival time of 167 days, without a statistically significant difference $(p=0.6)$ (-Fig. 2).
Table 1 Survival according to analyzed parameters

\begin{tabular}{|c|c|c|c|c|}
\hline Parameter & Subgroup & $\begin{array}{l}\text { Number of } \\
\text { patients }\end{array}$ & $\begin{array}{l}\text { Survival } \\
\text { (days) }\end{array}$ & $p$ \\
\hline \multirow{3}{*}{$\begin{array}{l}\text { Age } \\
\text { (years old) }\end{array}$} & $<60$ & 14 & 191 & \multirow[t]{3}{*}{$>0.05$} \\
\hline & $\begin{array}{l}>60 \text { and } \\
<75\end{array}$ & 15 & 185 & \\
\hline & $>75$ & 13 & 147 & \\
\hline \multirow[t]{2}{*}{ Gender } & Female & 19 & 150 & \multirow[t]{2}{*}{$>0.05$} \\
\hline & Male & 23 & 197 & \\
\hline \multirow[t]{2}{*}{ Karnofsky } & $<70$ & 18 & 103 & \multirow[t]{2}{*}{$<0.05^{\circ}$} \\
\hline & $\geq 70$ & 24 & 230 & \\
\hline \multirow[t]{4}{*}{ Location } & Unilobar & 19 & 228 & \multirow[t]{4}{*}{$<0.05^{\circ}$} \\
\hline & Multilobar & 9 & 196 & \\
\hline & Insular & 6 & 158 & \\
\hline & Deep & 8 & 40 & \\
\hline \multirow[t]{2}{*}{ Laterality } & Unilateral & 37 & 194 & \multirow[t]{2}{*}{$<0.05$} \\
\hline & Bilateral & 5 & 39 & \\
\hline \multirow{2}{*}{$\begin{array}{l}\text { Complica- } \\
\text { tions }\end{array}$} & Yes & 23 & 104 & \multirow[t]{2}{*}{$<0.05$} \\
\hline & No & 19 & 262 & \\
\hline
\end{tabular}

*: statistically significant when $p<0.05$.

\section{0 years-old}

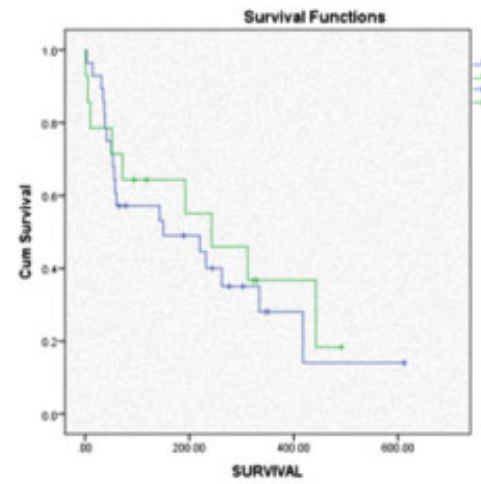

70 years-old

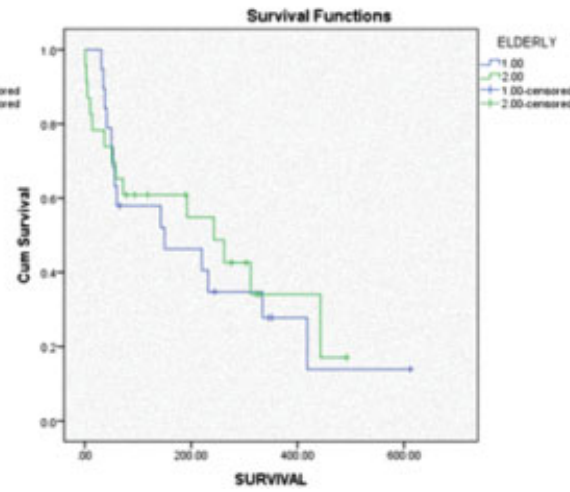

75 years-old

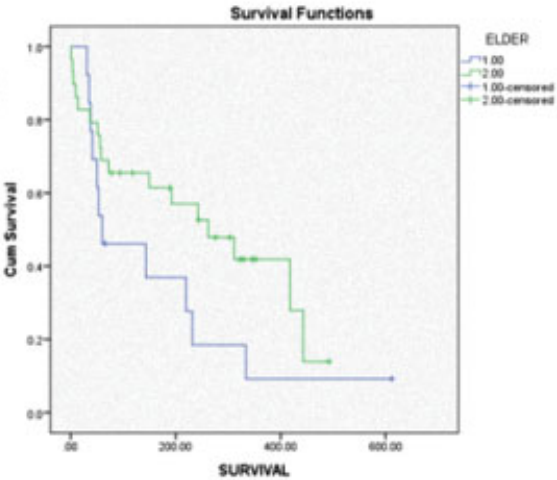

Fig. 2 Survival in days according to age. On the left, the threshold is 60 years old. In the middle, the threshold is 70 years old. On the right, the threshold is 75 years old. 


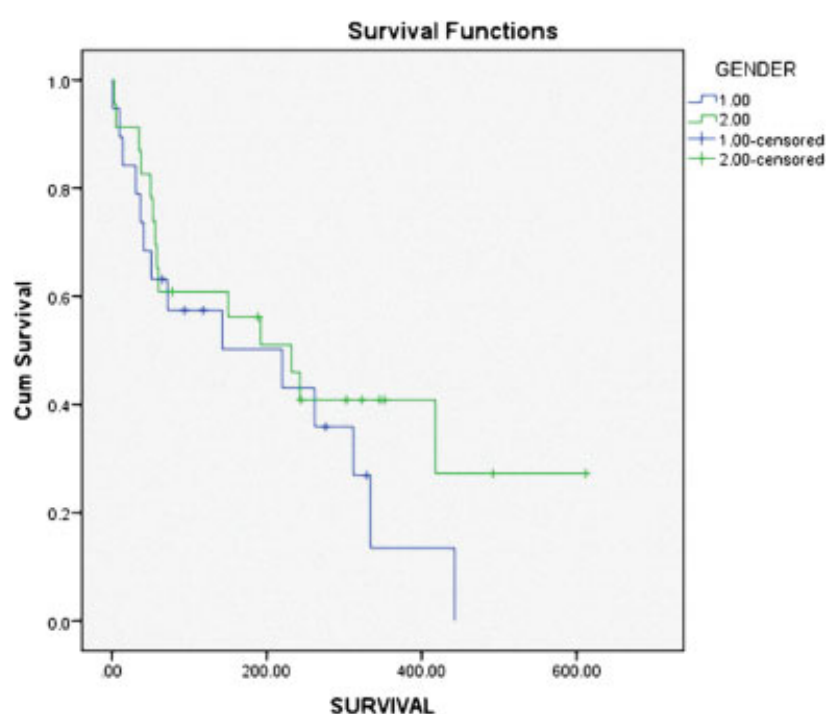

Fig. 3 Survival in days according to gender $(1=$ female; 2 = male $)$.

In the second scenario, patients $<70$ years old had a mean survival time of 183 days, while patients $>70$ years old had a mean survival time of 169 days, without a statistically significant difference ( $p=0.7$ ) (-Fig. 2).

In the third scenario, patients $<75$ years old had a mean survival time of 188 days, while patients $>75$ years old had a mean survival time of 147 days, without a statistically significant difference $(p=0.12)$ (-Fig. 2).

Comparing the survival time according to gender, there was no statistically significant difference between men and women $(p=0.3)$. The mean survival time was of 150 days in women and of 197 days in men (-Fig. 3).

\section{Karnofsky Scale}

We have divided the patients in two groups: those with KS $<70$ and those with $\mathrm{KS} \geq 70$. Eighteen patients ( $42 \%$ ) had $\mathrm{KS}<70$, and

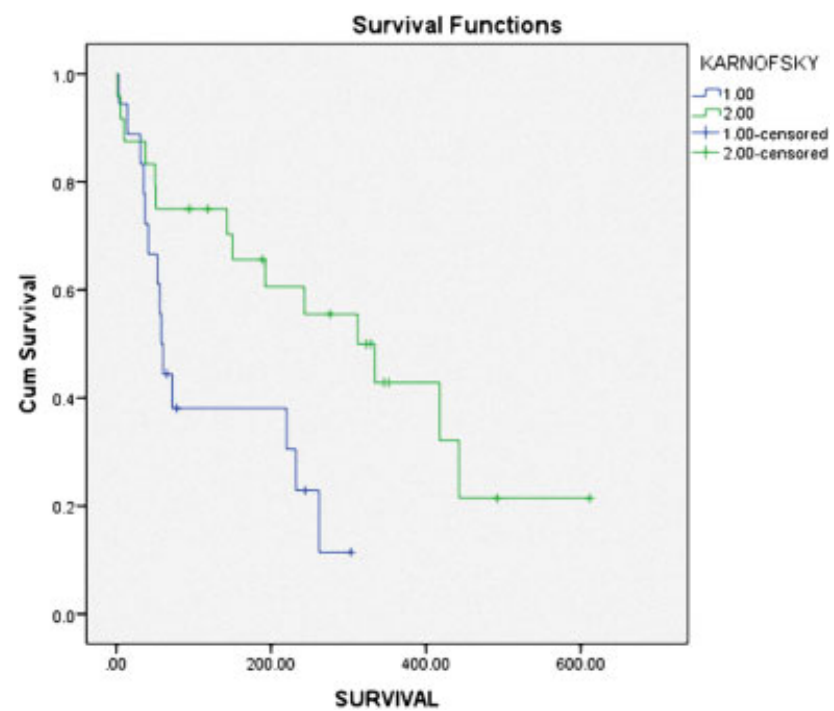

Fig. 4 Survival in days according to the Karnofsky Scale $(1=<70 ; 2=>70)$.

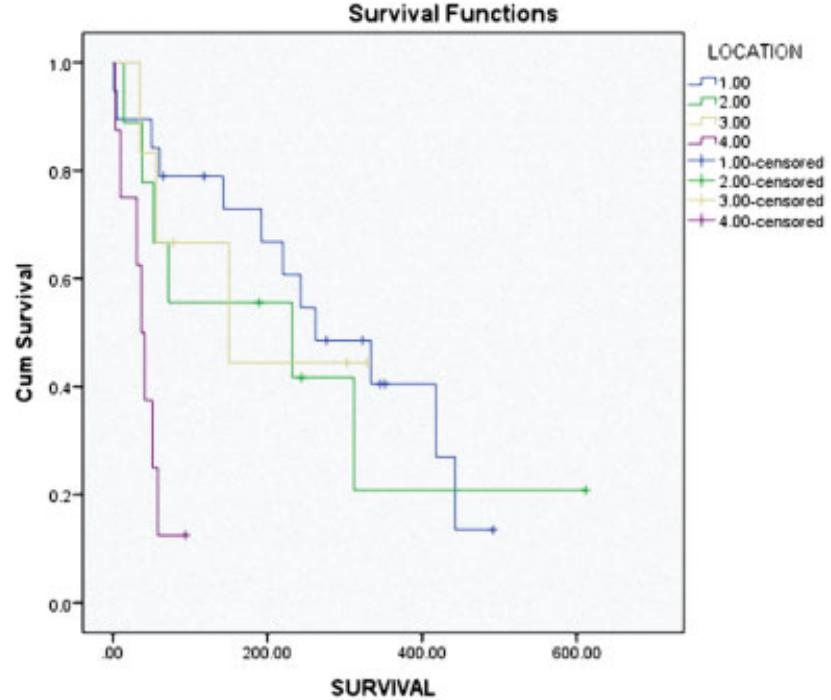

Fig. 5 Survival in days according to the location of the tumor $(1=$ unilobar; $2=$ multilobar; $3=$ insular; $4=$ deep $)$.

24 (58\%) had KS $>70$. The mean survival time in the KS $<70$ group was of 103 days, and of 230 days in the KS $>70$ group.

In - Fig. 4, we see the Kaplan-Meier curve analyzing both groups. There was a statistically significant difference in the survival rate between groups $(p=0.01)$. Patients with KS $>70$ had a better survival time than those with $\mathrm{KS}<70$.

\section{Location}

Glioblastomas were insular in 6 patients (14.3\%), multilobar in 9 (21.5\%), unilobar in 19 (45.2\%), and there were 8 (19\%) cases of deep-seated tumors.

The mean survival time was of 228 days in cases of unilobar tumors, of 196 days in multilobar tumors, of 158 days in insular tumors, and of 40 days in deep tumors.

In - Fig. 5, we show the survival curve according to the location of the tumor. Patients with deep tumors had the

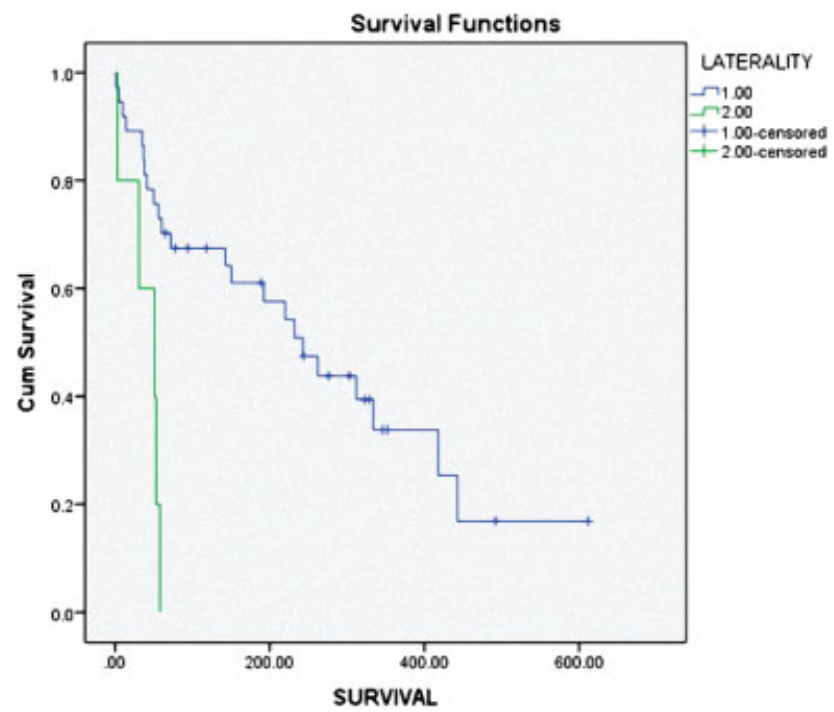

Fig. 6 Survival in days according to the laterality of the tumor ( 1 = unilateral; 2 = bilateral). 
worst survival time, which was statistically significant $(p=0.001)$.

\section{Laterality}

Glioblastomas were unilateral at the time of diagnosis in 37 patients (88\%), and bilateral in 5 patients (12\%).

The mean survival time was of 194 days in unilateral tumors and of 39 days in bilateral tumors. In - Fig. 6, we show the survival curve according to the laterality of the tumor. Patients with bilateral tumors at the time of diagnosis had the worst survival time, which was statistically significant $(p=0.001)$.

\section{Complications}

Out of the total of 42 patients, 23 (54\%) had 33 clinical or perioperative complications, which were: 2 pulmonary thromboembolisms; 5 cases of surgical site infection; 2 cases of hydrocephalus and need of definitive shunt; 7 cases of nosocomial pneumonia; 6 cases of urinary tract infection; 1 case of perioperative meningitis; 4 cases of surgical site hematomas; 1 cerebrospinal fluid fistula; 2 cases of worsening of neurological deficits; 1 brain abscess; and 1pharmacodermia after the use of phenytoin (-Table $\mathbf{2}$ ).

In - Fig. 7, we present the survival curves according to the presence of perioperative complications. Patients presenting with complications had a worse prognosis $(p=0.001)$. The mean survival time was of 262 days in patients without perioperative complications and of 104 days in those with perioperative complications.

Among the patients with perioperative complications, seven died before discharge, due directly to the surgery, being considered early complications. The other complications occurred after the patients were discharged. One case was of a patient with a deep-seated tumor; he was submitted to a stereotactic biopsy and deteriorated neurologically by the $10^{\text {th }}$ postoperative day. Another patient with a deepseated tumor was operated and remained in the intensive care unit (ICU) with pneumonia and died. Another patient with a unilobar tumor died on the $5^{\text {th }}$ postoperative day, just after discharge, due to a massive pulmonary embolism. Another patient with a unilobar tumor was submitted to surgery and had a postoperative wound infection, dying due

Table 2 Perioperative complications

\begin{tabular}{|l|l|}
\hline \multicolumn{2}{|l|}{ Complications } \\
\hline Clinical & Surgical \\
\hline Pneumonia (7) & Wound infection (5) \\
\hline DVT (1) & Hydrocephalus (2) \\
\hline PTE (2) & Meningitis (1) \\
\hline UTI (6) & Postoperative hematoma (4) \\
\hline Pharmacodermia (1) & CSF fistula (1) \\
\hline & Pre-operative deficits (2) \\
\hline & Cerebral abscess (1) \\
\hline
\end{tabular}

Abbreviations: CSF, cerebrospinal fluid; DVT, deep vein thrombosis; PTE, pulmonary thromboembolism; UTI, urinary tract infection.

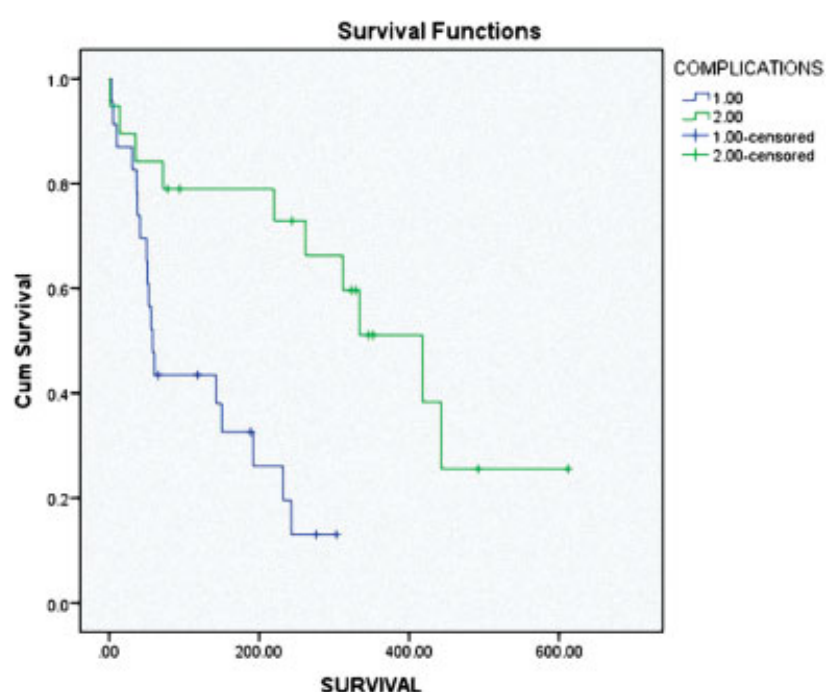

Fig. 7 Survival in days according to the presence of complications ( $1=$ with complications; 2 = without complications).

to Stevens-Johnson syndrome after being treated with antibiotics (vancomycin and cefepime). Another patient with an insular tumor was operated and remained in the ICU with pneumonia and died. Another patient with a deep tumor was operated in impaired neurological status and deteriorated quickly after surgery, dying on the $3^{\text {rd }}$ postoperative day. Finally, another patient with unilobar tumor acquired nosocomial pneumonia and died after surgery, although the surgical results were satisfactory.

Among the remaining 16 patients who presented with perioperative complications, only 4 (25\%) could initiate the adjuvant therapy. The other 12 patients could not initiate the adjuvant therapy due to pneumonia and hospitalization in 2 cases, urinary tract sepsis in 2 cases, wound dehiscence or infection in 2 cases, and temporary loss of follow-up in 3 cases. In two cases, there was an early clinical and neurological deterioration due to the progression of the disease, and the adjuvant therapy was contraindicated. Only one patient refused the adjuvant therapy.

The average time to begin the adjuvant therapy ranged from 30 days, in patients without perioperative complications, to 84 days, in patients with perioperative complications.

\section{Follow-up}

The follow-up time ranged from 4 to 24 months, with an average of 11.4 months. At the end of the follow-up (24 months), 29 patients (69\%) had died.

\section{Discussion}

The elderly constitute a heterogeneous population with a range of comorbid conditions, as well as functional, cognitive and physiological changes. Treatment decisions should be made in the context of a comprehensive assessment. Although elderly patients in good clinical status who are submitted to an unremarkable transoperative treatment may achieve maximal tumor resection and undergo standard 
chemotherapy and radiation therapy, other patients in a worse clinical status who face complications may not be ideal candidates for full treatment, deserving a less invasive approach. $^{1-20}$

Understanding the individual patient survival time profiles and the potential related factors has the potential to interfere with therapeutic targets and, therefore, to influence the surgical and clinical treatment planning. ${ }^{1-19}$

The current literature already affirms that age is the most important factor involved in survival time. The mean survival time of patients with GB is $\sim 18$ months, while in patients $>70$ years old this number decreases to 6 months. ${ }^{1-9}$ It is possible that this difference is due to different treatments proposed to elderly patients. In a retrospective study, Paszat et al revealed that only $46 \%$ of the elderly patients with GB received standard treatment (surgery + chemoradiation). ${ }^{2}$ Surely, other causes for these differences are related to comorbid diseases, to intolerance to medications, and to a low physiologic reserve. ${ }^{20-29}$

When analyzing the current evidence in the treatment of GB in the elderly, we can conclude that surgery has a key role in the treatment, increasing the quality of life (QOL) and the survival rate, and that a maximal and function preserving surgery is feasible and safe, not adding many risks. The factors which predict worse postoperative results are a low KS score, chronic pulmonary disease, large tumors $(>4 \mathrm{~cm})$, and previous neurological deficits. ${ }^{20-29}$

Subsequently, RT is also important after surgery, with a positive influence in survival and in symptom control. ${ }^{10-19}$ Hypofractionated radiotherapy is the preferred option to treat elderly patients, warranting the same results with higher adhesion and comfort. ${ }^{9-17}$ Additionally, chemotherapy is also effective and reveals a positive impact. Carmustine and the combination of procarzabine, lomustine and vincristine (PCV) should be avoided due to myelotoxicity, but TMZ is safe and changes the survival time in patients with 06-methylguanine-DNA methyltransferase (MGMT) methylation. In addition, bevacizumab significantly increased the overall survival time. Although elderly patients with GB have a poor prognosis, they may experience an enhanced survival time after the administration of the standard of care and the use of additional chemotherapeutics such as bevacizumab. ${ }^{20-29}$

In our analysis, we have confirmed that KS score, the location and laterality of the tumors, and complications during treatment are factors related to survival time. Gender was not associated with a worse prognosis, although men had better outcomes. Older patients suits really better. However, there was no statistically significant difference.

Older patients, with a low KS score, deep-seated tumors, and patients with perioperative complications had worst outcomes. On the other hand, younger patients, with a high KS score, unilobar tumors, without perioperative complications, had better outcomes. Additionally, perioperative complications not only decreased the survival time but increased the interval to begin proper adjuvant therapy, contributing to the deterioration of the clinical picture of these patients.

Thus, GBs may be treated following a standard protocol in elderly patients. In centers with a low rate of complications, surgery and perioperative chemotherapy and radiotherapy add survival time and QOL to these patients. Nevertheless, in patients with a low KS score, another treatment option should be applied, including isolated RT and/or chemotherapy.

The most important finding in our paper is the correlation between surgical complications and poor prognosis. Another important finding is that the administration of adjuvant therapy is essential in the treatment of GBs. The maximal survival time of elderly GB patients may be achieved with maximal surgical resection, but also with optimal operative conditions to minimize postoperative complications and better adjuvant therapy delivery in the appropriate time. A more elective way to submit these patients to surgery and to adjuvant therapy may positively impact their outcome.

Some limitations of the present study must be described. First, our sample was recruited from a single tertiary referral center. Second, the number of patients in each subgroup should have been greater. Another point that should be carefully analyzed is a potential bias regarding the location of the tumors and the KS scores of the patients. Perhaps, in patients with multilobar and deep-seated tumors, due to diffuse and eloquent brain involvement, the KS score is significantly lower than in patients with tumors involving insular and unilobar lesions. The outcome of these patients may be determined by the KS score rather than by the location itself. It should also be pointed out that our investigation did not use biomolecular and genetic markers, which are not available in our service. This may surely weaken our results and discussion but does not invalidate the survival curves presented.

Finally, we did not apply in our sample any QOL assessment tool. We strongly believe that QOL is very important in the context of these patients, since survival time and, above all, QOL, are paramount. However, our initial aim was to determine only for how long patients with GB lived. As we have confirmed, their survival time is limited and is surely associated with a poor QOL.

\section{Conclusions}

The location of the tumors, the KS score, and complications during treatment are factors related to survival time. Age has a clinical impact, but no statistically significant difference in survival time. Patients $>60$ years old, with a low KS score, deep-seated tumors, and patients with perioperative complications had worst outcomes.

Conflicts of Interest

The authors have no conflicts of interest to declare.

\section{References}

1 Yancik R. Cancer burden in the aged: an epidemiologic and demographic overview. Cancer 1997;80(07):1273-1283

2 Paszat L, Laperriere N, Groome P, Schulze K, Mackillop W, Holowaty E. A population-based study of glioblastoma multiforme. Int J Radiat Oncol Biol Phys 2001;51(01):100-107

3 Scott J, Tsai YY, Chinnaiyan P, Yu HH. Effectiveness of radiotherapy for elderly patients with glioblastoma. Int J Radiat Oncol Biol Phys 2011;81(01):206-210 
4 Chaichana KL, Chaichana KK, Olivi A, et al. Surgical outcomes for older patients with glioblastoma multiforme: preoperative factors associated with decreased survival. Clinical article. J Neurosurg 2011;114(03):587-594

5 Ewelt C, Goeppert M, Rapp M, Steiger HJ, Stummer W, Sabel M. Glioblastoma multiforme of the elderly: the prognostic effect of resection on survival. J Neurooncol 2011;103(03):611-618

6 Park HK, Koh YC, Song SW. The clinico-oncologic outcomes of elderly patients with glioblastoma after surgical resection followed by concomitant chemo-radiotherapy. Brain Tumor Res Treat 2014;2(02):69-75

7 Roa W, Brasher PM, Bauman G, et al. Abbreviated course of radiation therapy in older patients with glioblastoma multiforme: a prospective randomized clinical trial. J Clin Oncol 2004;22(09):1583-1588

8 Lutterbach J, Ostertag C. What is the appropriate radiotherapy protocol for older patients with newly diagnosed glioblastoma? J Clin Oncol 2005;23(12):2869-2870

9 Baker SD, Grochow LB. Pharmacology of cancer chemotherapy in the older person. Clin Geriatr Med 1997;13(01):169-183

10 Dinnes J, Cave C, Huang S, Milne R. A rapid and systematic review of the effectiveness of temozolomide for the treatment of recurrent malignant glioma. Br J Cancer 2002;86(04):501-505

11 Stewart LA. Chemotherapy in adult high-grade glioma: a systematic review and meta-analysis of individual patient data from 12 randomised trials. Lancet 2002;359(9311):1011-1018

12 Yin AA, Zhang LH, Cheng JX, et al. Radiotherapy plus concurrent or sequential temozolomide for glioblastoma in the elderly: a metaanalysis. PLoS One 2013;8(09):e74242

13 Fiorica F, Berretta M, Colosimo C, et al. Glioblastoma in elderly patients: safety and efficacy of adjuvant radiotherapy with concomitant temozolomide. Arch Gerontol Geriatr 2010;51(01):31-35

14 Gerstein J, Franz K, Steinbach JP, et al. Postoperative radiotherapy and concomitant temozolomide for elderly patients with glioblastoma. Radiother Oncol 2010;97(03):382-386

15 Minniti G, Lanzetta G, Scaringi C, et al. Phase II study of shortcourse radiotherapy plus concomitant and adjuvant temozolomide in elderly patients with glioblastoma. Int J Radiat Oncol Biol Phys 2012;83(01):93-99

16 Stupp R, Hegi ME, Mason WP, et al; European Organisation for Research and Treatment of Cancer Brain Tumour and Radiation Oncology Groups; National Cancer Institute of Canada Clinical Trials Group. Effects of radiotherapy with concomitant and adjuvant temozolomide versus radiotherapy alone on survival in glioblastoma in a randomised phase III study: 5-year analysis of the EORTC-NCIC trial. Lancet Oncol 2009;10(05):459-466
17 Wick W, Platten M, Meisner C, et al; NOA-08 Study Group of Neuro-oncology Working Group (NOA) of German Cancer Society. Temozolomide chemotherapy alone versus radiotherapy alone for malignant astrocytoma in the elderly: the NOA-08 randomised, phase 3 trial. Lancet Oncol 2012;13(07):707-715

18 Malmström A, Grønberg BH, Marosi C, et al; Nordic Clinical Brain Tumour Study Group (NCBTSG). Temozolomide versus standard 6-week radiotherapy versus hypofractionated radiotherapy in patients older than 60 years with glioblastoma: the Nordic randomised, phase 3 trial. Lancet Oncol 2012;13(09): 916-926

19 Álvarez de Eulate-Beramendi S, Álvarez-Vega MA, Balbin M, Sanchez-Pitiot A, Vallina-Alvarez A, Martino-González J. Prognostic factors and survival study in high-grade glioma in the elderly. Br J Neurosurg 2016;30(03):330-336

20 Almenawer SA, Badhiwala JH, Alhazzani W, et al. Biopsy versus partial versus gross total resection in older patients with highgrade glioma: a systematic review and meta-analysis. Neurooncol 2015;17(06):868-881

21 Ferguson M, Rodrigues G, Cao J, Bauman G. Management of highgrade gliomas in the elderly. Semin Radiat Oncol 2014;24(04): 279-288

22 Gállego Pérez-Larraya J, Delattre JY. Management of elderly patients with gliomas. Oncologist 2014;19(12):1258-1267

23 Tabouret E, Tassy L, Chinot O, Crétel E, Retornaz F, Rousseau F. High-grade glioma in elderly patients: can the oncogeriatrician help? Clin Interv Aging 2013;8:1617-1624

24 Zarnett OJ, Sahgal A, Gosio J, et al. Treatment of elderly patients with glioblastoma: a systematic evidence-based analysis. JAMA Neurol 2015;72(05):589-596

25 Franceschi E, Depenni R, Paccapelo A, et al; PERNO Study Group. Which elderly newly diagnosed glioblastoma patients can benefit from radiotherapy and temozolomide? A PERNO prospective study. J Neurooncol 2016;128(01):157-162

26 Mason M, Laperriere N, Wick W, et al. Glioblastoma in the elderly: making sense of the evidence. Neurooncol Pract. 2016;3(02):77-86

27 Arvold ND, Reardon DA. Treatment options and outcomes for glioblastoma in the elderly patient. Clin Interv Aging 2014; 9:357-367

28 Burton E, Ugiliweneza B, Woo S, Skirboll S, Boaky M. A Surveillance, Epidemiology and End Results-Medicare data analysis of elderly patients with glioblastoma multiforme: Treatment patterns, outcomes and cost. Mol Clin Oncol 2015;3(05):971-978

29 Babu R, Komisarow JM, Agarwal VJ, et al. Glioblastoma in the elderly: the effect of aggressive and modern therapies on survival. J Neurosurg 2016;124(04):998-1007 